\title{
Digital technologies in modern higher educational space: analysis of risks and threats
}

\author{
Victoria Kotlyarova ${ }^{1 *}$, Andrey Rudenko ${ }^{1}$, Natalia Yaksa $^{2}$, and Marina Shubina ${ }^{1}$ \\ ${ }^{1}$ Institute of Service and Entrepreneurship (branch) Don State Technical University in Shakhty, \\ 346500, Shakhty, Russia \\ ${ }^{2}$ V.I. Vernadsky Crimean Federal University, Taurida Academy, Faculty of Psychology, Republic of \\ Crimea, 295007, Simferopol, Russia
}

\begin{abstract}
At present, Russia faces a strategic task related to building a course aimed at a breakthrough in the scientific, technological and socioeconomic development of the country. This development is inextricably linked with the digital economy, which, in turn, is impossible without the digitalization of education. The essence of digitalization of education is to achieve high performance in the educational process using digital technologies. It is noted, that within the framework of the digital transformation of education, the content of education, methods, forms of educational work, forms of assessing the results achieved by students are changing. On the one hand, this process is aimed at developing a digital educational environment in order to improve the educational results of each student, but on the other hand, when using digital technologies in the higher educational space, the following risks arise: the risk of dehumanization, the risk of spiritual lumpenization, the threat to the fundamental component of traditional education caused by the promotion of "educational services", the risk of loss of cognitive competencies, the risk of technologization and robotization, the deepening crisis of intellectual culture, the threat to the creative development of the individual, the risk of social exclusion.
\end{abstract}

\section{Introduction}

Currently, we are witnessing the active introduction of digital technologies into the modern world, which leads to qualitative changes in the economic sphere. The digital economy cannot be built without quality digital education. This was stated in the speech of the First Deputy Chairman of the State Duma Committee on Education and Science, which took place in 2019 within the framework of the State Duma Committee on Education and Science. Thus, we see a close connection between the digital education process and the development of modern economy.

Russia faces a strategic task: in the coming years to build a course aimed at a breakthrough in the scientific, technological and socio-economic development of the country. Such a course cannot be built without the use of digital technologies. These technologies, penetrating into the life of society, become an integral part of the process of

* Corresponding author: biktoria66@mail.ru 
modern education. By introducing new information and communication technologies into teaching, the educational process and the institution of education as a whole are being transformed. Technological progress and digitalization are making education mobile, open and strengthening the role of non-formal education.

The intensive introduction of digital technologies into the higher educational space, along with certain advantages [1], also generates a number of risks associated with organizational, substantive and methodological issues [2]. The introduction of digital technologies in the educational process of higher education entails the creation of a digital educational environment, the development of which takes a long time for both the teaching staff and students. It should also be noted that the process of digitalization of the educational space is not fully controllable and often there are problems of a structural, economic and technological nature.

Currently, modern researchers are actively addressing the problem of digitalization of education, since the role of digital technologies in the educational space of higher school is increasing and the main subjects of the educational space are immersed in the digital environment. Within the framework of existing works, researchers turn to the digitalization of education in general; consider the creation and functioning of a digital educational environment, the use of information and communication technologies in the education process, the creation of online courses and the use of distance learning in education $[3 ; 4$; 5]. In our opinion, it is very important to comprehensively analyze the risks and threats posed by digital technologies in the modern educational space. This analysis helps to understand the weaknesses of this process and to eliminate them at the initial stage. In this regard, we turn to the consideration of the risks and threats that arise in the higher educational space due to the introduction of digital technologies.

\section{Methodology}

The Institute of Education is of interest to many researchers. Many research works are devoted to the functions of the institution of education [6]. Describing the functions of the institution of education, scientists highlight the criteria for the effectiveness of the educational system, where the economy plays an important role, which acts as a consumer of the final product of the educational system - qualified personnel, recognizing the functionality of the system or stating the dysfunctionality of education.

Currently, huge amounts of works are aimed at considering the reform of this institution and the transformation of the educational process $[7 ; 8 ; 9]$. The educational system changes in accordance with the requirements and needs of modern society. The aspects of the education system depend on interconnected factors. These factors include technological progress, globalization, a dramatically increased number of people with higher education, transformational processes in the economy and in the labor market [10].

When studying the issue of modernization of education, the problem of digitalization occupies an important place [11]. In order to make the educational system more flexible, mobile and accessible to all citizens, information and communication technologies are being introduced and a digital educational space is being created. In the educational process, software and hardware tools and methods are actively used, aimed at collecting, storing, processing, analyzing and broadcasting information among all participants in the educational process [12]. The goal of digitalization of education is to reduce the labor intensity of processes through the use of information resources.

As part of the consideration of the issue of digitalization of education, researchers turn to the study of the competence model of teaching students and the consideration of digital competencies that a teacher should have $[4 ; 13]$. The competencies that a modern teacher possesses are expressed in digital literacy and digital skills of a teacher in order to use the 
full potential of digital technologies for teaching, and mastering a complex of competencies by modern students.

In many works, researchers note the emergence of many risks and threats already at the stage of the primary digitalization processes in the modern higher educational space, affecting information security and cyber security as part of the cybersocialization of youth in the formation of a digital society.

The issues of information culture of young people and the problem of risks and threats (including digital risks) for modern youth and their health are given special attention by researchers $[14 ; 15 ; 16]$. The influence of the Internet on the formation of social attitudes of modern young people is actively considered, while noting not very high level of information culture of youth.

Based on the literature analyzed, we believe that it is very important to dwell in more detail on the analysis of the risks that may arise due to the introduction of digital technologies in the higher educational environment.

In this work, we turn to education as one of the important social institutions (E. Durkheim, M. Weber), which has certain norms and rules, which in turn are subject to changes due to transformational processes in society. Due to the entry of digitalization into education, the functions of education also change ( $T$. Parsons). With the change in functions, the educational process is being transformed, which is reflected both positively and negatively on all actors in education.

\section{Results}

The digitalization of education includes mechanisms aimed at improving educational results. With the digital transformation of education, the content of education, methods, forms of educational work, forms of assessing the results achieved are changing. This process is aimed at developing a digital educational environment in order to improve the educational results of each student.

Communication flows are constantly circulating in the educational space: external interaction with social institutions and social groups outside the educational organization, and internal flows - relations built within the walls of the university between employees and students of the educational institution. The introduction of digital technologies makes it possible to optimize and improve the communication process (Fig.1).

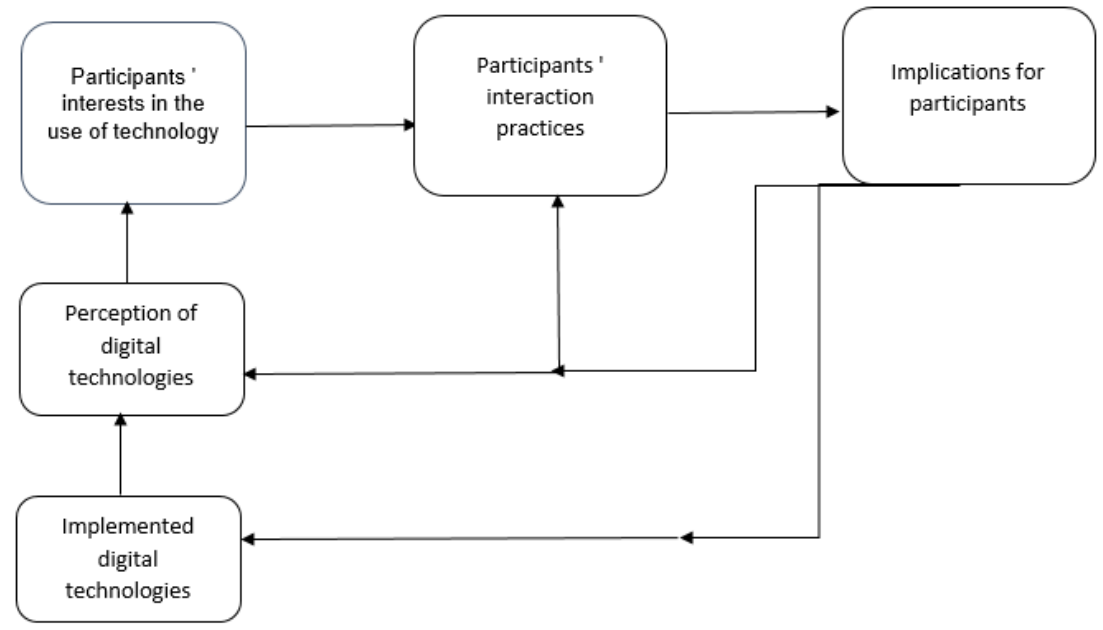

Fig. 1. The impact of digital technologies on the interaction practices of the main participants of the higher education system 
The integration of information resources into the educational process allows us to create a unified digital educational environment. The created digital environment provides access to electronic materials, enables participants in the academic process to communicate with each other indirectly. Moodle and Teams platforms are very popular for work among higher education institutions nowadays. On these platforms, teachers have the opportunity to create materials for lectures and practical assignments, post photos, videos and audio content, conduct video conferences in teams, check test assignments, and evaluate students.

The digital educational environment also includes the use of technical means and information technologies in the learning process. Currently, teachers present the discipline material on electronic projectors and interactive whiteboards, using presentation materials or videos.

Digital educational environment is necessary both within the framework of traditional education and when conducting classes in a distance format. As part of traditional learning, students and teachers can exchange electronic textbooks, presentations and other content via corporate email. Teachers have the opportunity to assess students in an electronic journal, and students' assessments in disciplines from the curriculum are displayed in their personal offices.

\section{Discussion}

Thus, a single digital environment really allows the teacher to stay in touch with students at all times, actively monitor and advise them. However, there are also certain risks. Despite the fact that the term "risk" is very actively used in modern research, there is no single approach to this concept. It should be noted, that the risk has environmental and operational aspects. The environmental aspect is associated with the conditions of human life in conditions of uncertainty, and the operational aspect allows a person to make a choice within these conditions [15].

In this work, the object of our study is to identify risks and threats in the context of digitalization of the higher educational space. As part of the study of these risks and threats, we rely on the concepts developed by scientists in the field of pedagogy, psychology and sociology of education.

Based on our analysis, we can identify a number of risks and threats arising from the introduction of digital technologies into the modern educational space of higher education.

Despite the fact that the use of digital technologies in education makes it possible to create new opportunities for reflection for both students and teaching staff, there is a risk of dehumanization [17]. Digitalization of education in the form it exists today can bring side effects: young people are freed from the context of social and cultural ties; they acquire the status of digital people, where identity and individualism can be lost. That is, the humanistic potential of youth is being traumatized. In the youth consciousness, the position begins to dominate that education is a service provided by the university, and the ability to earn money is of paramount importance for young people. To minimize the risks associated with dehumanization, it is necessary to integrate digital education into the circuit of humanistically oriented education [18].

Since the value vector in relation to education is shifting, and young people perceive education as a service, there is a threat of destruction of the fundamental component of traditional education due to the promotion of "educational services". Young people believe that the university provides a service for which some students pay money, as they study on a contractual basis. In this regard, the value of education in the eyes of students decreases. The educational paradigm is also transforming - from knowledge to activity, which in the eyes of students sometimes devalues the acquired theoretical knowledge and raises the value of practical skills. In our opinion, this is not correct. The educational process can be 
integral, harmonious and high quality only if it combines the translation of both theoretical knowledge and practical skills.

The use of information technology in the learning process can lead to the risk of technologization and robotization. In the framework of some educational programs, specialists use artificial intelligence technologies. For example, the work of chat bots, which could free teachers from the routine work of collecting homework from students, advise applicants when entering a university. What are the consequences? We believe that there may be a change in the requirements for faculty - the ability to work with artificial intelligence technologies. Reducing the need for an "intelligent" specialist in favor of a technological image. Very often, digital technologies are viewed by the university vertical as a tool to save on teaching hours, as savings on full-time teachers.

It is also worth noting the fact that there is a risk of loss of cognitive competence. Due to the fact that students actively learn to work with cloud storage, digital platforms, learn a variety of online communication, gain skills in working with "big data", master multitasking skills, sometimes traditional cognitive skills are lost - logic, reading, calculation, and writing. Many students are accustomed to the fact that a program can correct mistakes in writing, a special calculator will do the calculation, and you can teach a computer to think with the help of a special program. Nevertheless, every young person should remember that he will not always have a computer or a telephone at his fingertips, so cognitive competencies still need to be preserved and developed, rather than shifting the emphasis to digital competencies.

We emphasize that for modern society, the intellectual culture of a student is important and really needed. In our opinion, digitalization of education can deepen the crisis of students' intellectual culture. Constant interaction with information technology smartphones, tablets, laptops, smart watches, can lead to the fact that the young person will not be able to think for himself. It is also worth noting that excessive use of the Internet and immersion in the media space affects the formation of the consciousness of young people; young people sometimes do not know how to think critically, take all information at face value and cannot clear information noise from truthful and valuable information.

Digitalization of education can also threaten the creative development of the individual. The computer is not conducive to creativity, even in the context of simulation. The machine only helps the teacher to create a learning environment, which only contributes to the formation of creative thinking in the learner. The information environment itself does not form this thinking.

In addition, digitalization, namely the active use of information technology, increases the separation of learning from the upbringing process. For example, in distance learning, the principle of individualization is very clearly traced, within which it is believed that each student is left alone with a computer, which in turn can lead to the risk of spiritual lumpenization. Spiritual lumpenization is closely related to the crisis of the value system developing in the process of education, which, as we see, is minimized in the process of digitalization of the educational system [19].

The development of digitalization of education will contribute to the growth of exclusion between students and teachers. Alienation is also observed in the relations between students, which, among other things, finds its continuation in the network in the form of cybertrolling and cyberbullying.

\section{Conclusions}

Our analysis showed that the use of digital technologies in education creates conditions for updating the planned educational results through the improvement of planning and organization of the educational process. Digitalization involves the use of active teaching 
methods and the transition to individualization, which will make the educational process more effective. On the one hand, this process is aimed at developing a digital educational environment in order to improve the educational results of each student. On the other hand, when using digital technologies in the higher educational space, the following risks arise: the risk of dehumanization, the risk of spiritual lumpenization, the threat of losing the fundamental component of traditional education as a result of promoting "educational services", the risk of losing cognitive competencies, the risk of technologization and robotization, the deepening crisis of intellectual culture, the threat to the creative development of the individual, the risk of social exclusion.

The digitalization that takes place within the framework of education affects all levels of education. This process is impossible without the active participation of students, teachers, and researchers, employees of the administrative corps, employers, government authorities and representatives of the public. For the successful application of digital technologies in education, universities need to invest in digital training programs for employees of an educational organization. There must be a feedback from employees. The transition to digital education necessarily requires supporting activities organized by universities. These activities are aimed at introducing changes in the educational institution: providing assistance to academic staff who shape trends in the development of digital skills. It is also necessary to form working groups of university staff that could improve the overall level of digital literacy. These efforts, in our opinion, can help to introduce digital technologies into the higher education space more effectively.

\section{References}

1. N.V. Dneprovskaya, I.V. Shevtsova, Higher education in Russia 12, 144-155 (2020). DOI: 10.31992/0869-3617-2020-29-12-144-155.

2. O.V. Yureva, L.A. Burganova, O.Y. Kukushkina, G.P. Myagkov, D.V. Syradoev, Universal Journal of Educational Research 8(11B), 5965-5971 (2020) doi: 10.13189/ujer.2020.082232.

3. D.G. Arseniev, I.R. Trostinskaya, E.G. Pozdeeva, Processes of changes in the educational environment under the influence of digital technologies, (SPBPU IDE '19), International Scientific Conference on Innovations in Digital Economy 3377547, (2019) doi: 10.1145/3372177.3377547.

4. O. Zabolotska, N. Zhyliak, N. Hevchuk, N. Petrenko, O. Alieko, Journal of Optimization in Industrial Engineering 14(1), 43-50 (2021)

5. W. Zhao, X. Li, W. Zhang, International Conference on Geometry and Graphics 675680 (2021) doi: 10.1007/978-3-030-63403-2_60.

6. K.V. Vodenko, M.A. Komissarova, M.M. Kulikov, Studies in Systems, Decision and Control 169, 183-192 (2019). doi: 10.1007/978-3-319-94310-7_18.

7. M. Maslovskii, K. Lehtisaariб Soviet modernization and its legacies from the perspective of civilizational analysis. Philosophical and Cultural Interpretations of Russian Modernisation (Routledge, London, 2017)

8. I. Abankina, I. Scherbakova, Journal of the European Higher Education Area 3, 3-25 (2013)

9. S. Guri-Rosenblit, The European Higher Education Area 15, 13-26 (2015) doi: 10.1007/978-3-319-20877-0_2.

10. J.H. Schuster, M.J. Finkelstein, The American Faculty: the Restructuring of Academic Work and Careers (the Johns Hopkins University Press, Baltimor, 2006). 
11. K. Harpreet, International Journal of Applied Research SP4, 286-288 (2019)

12. K. Ratheeswari, Journal of Applied and Advanced Research 3(S1), 45 (2018) doi: 10.21839/jaar.2018.v3iS1.169.

13. E. Neupokoeva, N. Chapaev, I. Suslova, N. Khokhlova, A. Sosnin, Thinking Skills and Creativity 39, 100753 (2021) doi: 10.17853/1994-5639-2016-3-106-127.

14. K. Chikaeva, L. Scherbakova, E. Karapetyan, A. Latysheva, S. Kosinov, S. Samygin, Revista San Gregorio 27, 300-309 (2018) doi: 10.17853/1994-5639-2016-3-106-127.

15. C. Williams, V. Chuprov, J. Zubok, Youth, risk and Russian modernity (Taylor and Francis, London, 2018).

16. J. Bustillo, The Digital Divide. Neoliberal Imperatives and Education (In: Isaacs S. (eds). European Social Problems. Routledge, London and New York, 2017).

17. N.Yu. Belikova, E.U. Ponomareva, Revista Gênero e Direito 9(4), 846-859 (2020)

18. E.A. Karapetyan, N.Kh. Gafiatulina, V.M. Efimova, Revista Gênero e Direito 9(4), $830-845$ (2020)

19. N.Yu. Belikova, A.V. Rachipa, I.A. Yankina, et al., Revista Turismo Estudos \& Práticas S4, 16 (2020) 